\title{
All that is red is not blood!
}

A 62-year-old woman presented for screening colonoscopy after a 24-hour clear-liquid diet and Colyte preparation. Frank blood was noted from the point of colonoscope insertion up to the terminal ileum ( $\bullet$ Fig. 1 a). Aspirate tested negative with the hemoccult card. Using narrowband imaging (NBI) the "red liquid" appeared cyan blue ( $\boldsymbol{F i g .} \mathbf{1} \mathbf{b}$ ). Upon further questioning during recovery, the patient reported eating red jello.

NBI is an alternative light-wavelength capture system that filters light in the visible spectrum, except for narrow bands in the blue and green wavelengths ( $415 \mathrm{~nm}$ and $540 \mathrm{~nm}$, respectively) [1] ( $\bullet$ Fig. 3). The peak absorption spectrum of red dye is $502-518 \mathrm{~nm}$ and appears as a cyan color whereas oxyhemoglobin is absorbed at $415 \mathrm{~nm}$ and appears as dark maroon. As shown in $\odot$ Figs. $1 \mathrm{a}$ and $\mathbf{2 a}$, red jello and post-polypectomy bleeding appeared indistinguishable under white light. Even the most sophisticated of tools, NBI, has demonstrated here a simple clinical use in differentiating between blood and other
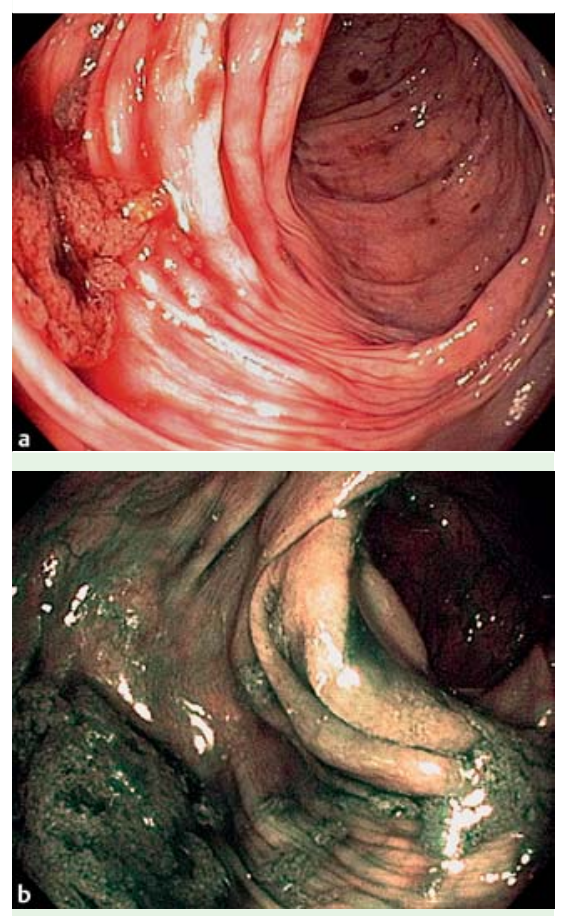

Fig. 1 Screening colonoscopy following ingestion of red jello. a Red liquid in colon lumen seen under white light. b Under the blue light of narrow-band imaging, the red dye in the jello (dye No. 40) appears blue-green.
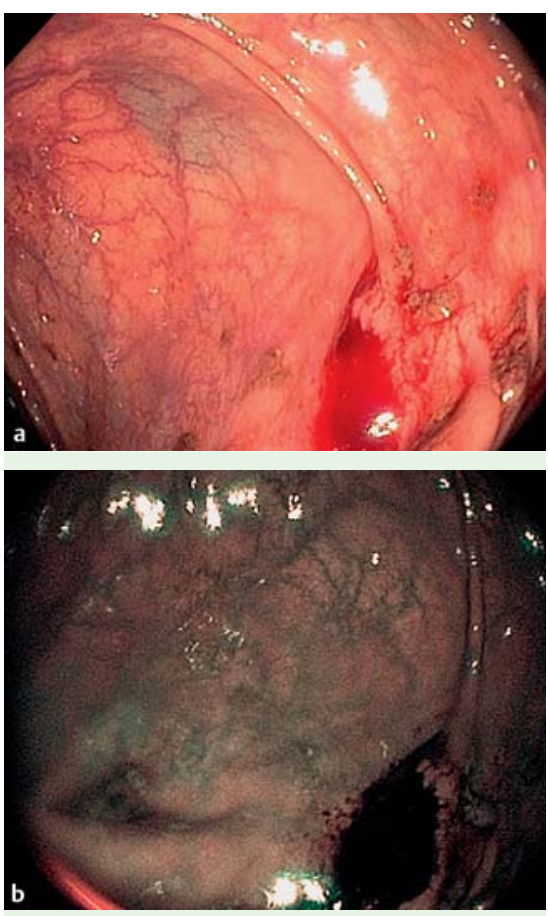

Fig. 2 Bleeding from recent polypectomy site. a Seen under white light. b Seen under blue light; note the dark maroon color of the blood.

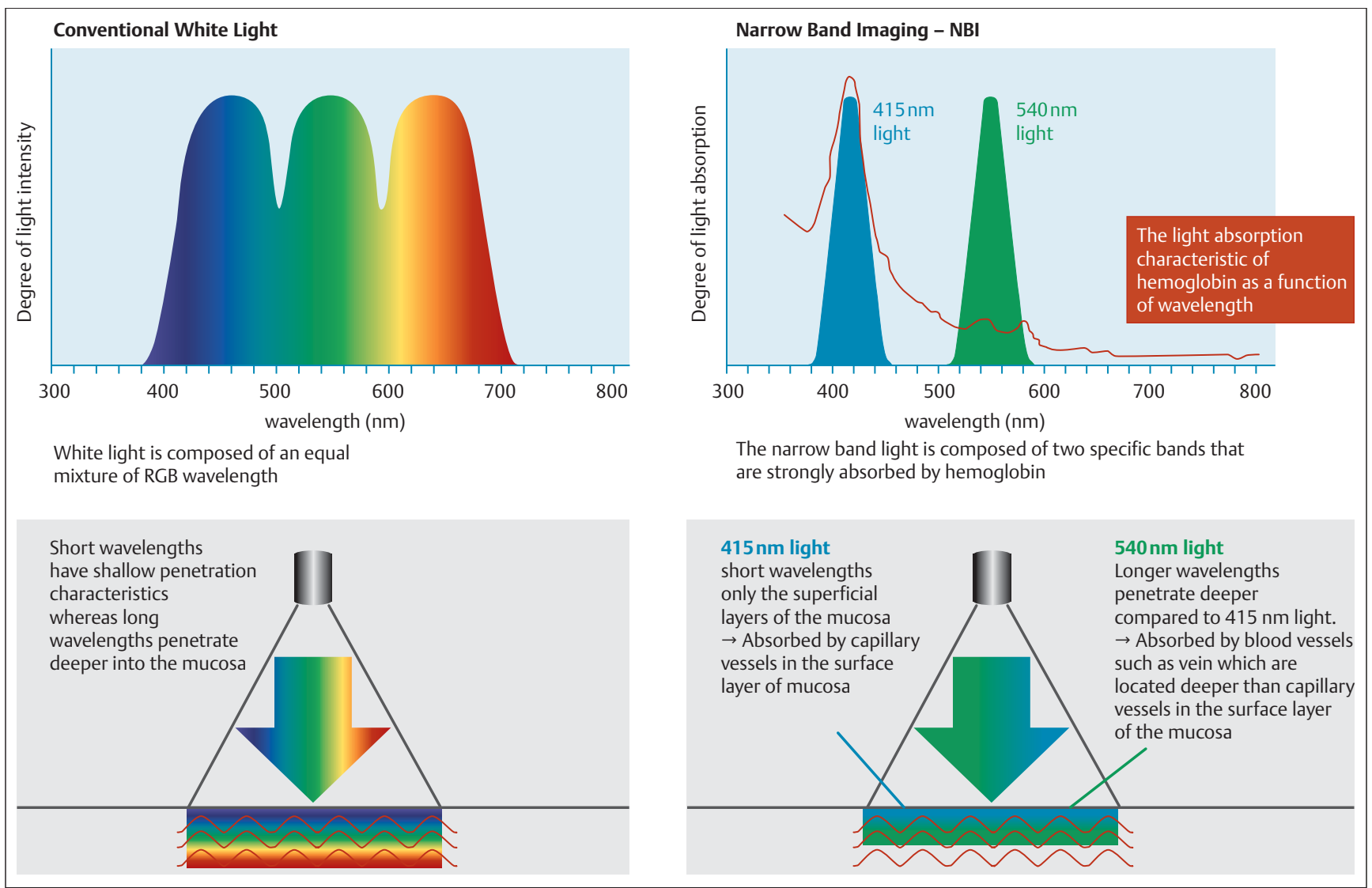

Fig. 3 Maximum absorptive capacity of hemoglobin at a wavelength of $415 \mathrm{~nm}$. Adapted with permission from Olympus Europe (www.olympus-europa.com). 
red substances. We suspect that this is not the first or the last case of "red jello stool" [2].

\section{Competing interests: None}

Endoscopy_UCTN_Code_CPL_1AJ_2AI
A. Soloman, M. Merheb, D. R. Ferguson Division of Gastroenterology, MetroHealth Medical Center, Case Western University, Cleveland, Ohio, USA

\section{References}

1 Kuznetsov K. Narrow-band imaging: potential and limitations. Endoscopy 2006; 38: $76-81$

2 Sullivan SN. Red jello stool and red dye-arrhea. J Clin Gastroenterology 1993; 16: 178
Bibliography

DOI $10.1055 / \mathrm{s}-0029-1244119$

Endoscopy 2010; 42: E229-E230

(c) Georg Thieme Verlag KG Stuttgart · New York . ISSN 0013-726X

\section{Corresponding author}

\section{A. Soloman, DO}

Division of Gastroenterology, MetroHealth Medical Center, Case Western University 2500 MetroHealth Dr.

Cleveland

$\mathrm{OH} 44109$

USA

Fax: +1-216-778-4873

asoloman@metrohealth.org 